\title{
Interfaces
}

\section{Pigment, light, paper, screen; formats as interacting multi-dimensional creative works}

\section{Tess Baxter}

\section{Q OpenEdition \\ 1 Journals}

Electronic version

URL: https://journals.openedition.org/interfaces/3905

DOI: 10.4000/interfaces.3905

ISSN: 2647-6754

Publisher:

Université de Bourgogne, Université de Paris, College of the Holy Cross

\section{Electronic reference}

Tess Baxter, "Pigment, light, paper, screen; formats as interacting multi-dimensional creative works", Interfaces [Online], 46 | 2021, Online since 15 December 2021, connection on 16 June 2022. URL: http://journals.openedition.org/interfaces/3905 ; DOI: https://doi.org/10.4000/interfaces.3905

This text was automatically generated on 16 June 2022.

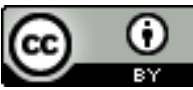

Les contenus de la revue Interfaces sont mis à disposition selon les termes de la Licence Creative Commons Attribution 4.0 International. 


\title{
Pigment, light, paper, screen; formats as interacting multi- dimensional creative works
}

\author{
Tess Baxter
}

\section{AUTHOR'S NOTE}

All images in the illustrations are copyright of Tess Baxter, sometimes under the pseudonym of Tizzy Canucci. The overlaid archive images within them are in the public domain; Illustrations 1-6, The City (Steiner and van Dyke) and Illustration 7, The Great Northern Sea Route (Frolenko). Illustrations 2 and 7 have been published as Creative Commons BY-NC-SA (Creative Commons).

\section{Introduction}

1 I work in a space where format is constantly disrupted. I produce art out of the virtual world of Second Life, a three-dimensional space, under the pseudonym of Tizzy Canucci. The material in it is modelled in three dimensions, but it originates as two. I make visual images of that three-dimensional space which I turn back into twodimensional moving images as video art. However, the process of editing is not just about the visual but audio is also crucial. The two play with time and size, physicality and materiality, origins and relationships, and this constitutes a multi-dimensional reworking of formats, not just spatial measurement.

2 My latest printmaking practice takes still images, produced as moving images as light on screen, and turns them into prints using etched plates to press ink on paper, in an individually crafted mechanical process ${ }^{1}$. I see this as playing with the light-space-time structures to allow the image to shine (McKenzie 71). The technical aspects of the process are secondary, although still relevant and of interest. 
3 In this way of working, formats cease to be simple categories or labels or fixed dimensions, but are available to be played with in a process of constant reinterpretation and translation. When making video in Second Life, I regard just recording the three-dimensional objects made by others as a failure - I should add my own creative interpretation, and it is in the rhythm of editing that I introduce my ideas of meaning (Merleau-Ponty 1964, 57). Each work is experimental and unique, and not definitive or exclusive in terms of either the artist or the format. I work with spaces that are free of copyright restrictions, are often public domain or creative commons, and what I produce follows the same principles. As such, it rejects the idea that only one creative image is possible or allowed. It permits - indeed encourages - the idea that creativity can be reworked, and so that format is mutable and can be re-interpreted imaginatively. In taking my practice into printmaking, I was aware that audiences interpret moving images and still images differently and I wanted to work and play with that. Space and time are essential and integral to both place and practice where I work, but in each it is perceived in different ways going beyond size and shape as a simple defining format.

4 In this paper I will take Future City (Canucci) as an example of my video art, and discuss how formats alter both going into and coming out of it, from the component parts to the creativity that emerges as printmaking. Indeed, technologies are never obvious or unambiguous, but are an interpretation of what we learn from experience, and from others (Grint and Woolgar, 32). In common with my other video art, the basis of Future City (Canucci) is video recorded inside a games world, edited with work that came from the outside or "real" world, and in so doing crosses the boundaries into literature, film and archive material. This dynamic works with different material and media types to bridge time and space, meanings and sensory experiences. In doing so, the sound and visuals of Future City span the main definitions of format in the Oxford English Dictionary (OED).

5 The OED lists several definitions for format, but there are three main ones, two nouns and one verb. The nouns are "Shape and size of a book, e.g. octavo, quarto, etc." and "A style or manner of arrangement or presentation; a mode of procedure" ("Format, n."). The verb is, "To arrange or put into a format: used chiefly in connection with Computing" ("Format, v."). The noun was first published in 1897 and predates the verb, first published in 1972. The older noun form primarily describes the form of objects, with action secondary. The more contemporary verb reflects the computer as a tool and how file formats are organised within them, and this relates to how they are thought about or played with. Lying beneath that difference between the nouns and verb is technological innovation. Printing press technology connects with the first noun and computer technology with the verb; both were significant technological innovations leading to cultural change (Wight; Gregory et al., xvii).

6 But also contained within those definitions are perceptions of space. If we take the noun definitions in the context of books, the first noun describes the outside as a threedimensional container (size and shape), and the second the content as a twodimensional formation of words and images on the page (manner of arrangement). One would enter the container to consider the content. The verb, in contrast, relates to the implications of computers; even while typing words that are apparently inside the machine, one remains connected to outside space, like using a conventional mechanical typewriter with one's fingers. In the context of my practice, a virtual world can be 
entered as a three-dimensional space and navigated with an avatar in a way not possible with a book. While my avatar is a three-dimensional object in a threedimensional world, "a thing among things" (Merleau-Ponty 1969, 136), that physical copresence still requires my imagination to work with the sense of being there in that space. As Welsh claims, each form of media reframes and reconfigures, and consequently remixes ideas in our minds $(\mathrm{x})$. That reframing by media inevitably changes shape, size and format, and that cannot be divorced from perception, imagination, and a sense of immersion (Krzywinska and King 41).

7 Technologies are constructed, or written, and used, or read, so technology can be seen as text (Grint and Woolgar 70). This raises another set of relationships between reality and virtuality, between experiences such as reading, imagination and immersivity, and objects such as books, games or computers (Emerson 1, 2; Welsh vii-2). Historically, during the $18^{\text {th }}$ century, concern was expressed about women becoming lost in reading and immersed in novels, something that Jane Austen chose to explore in her writing (Bray 144-55). Similarly, in the early $20^{\text {th }}$ century, Establishment figures in Britain expressed concern about how the working classes were simply seeking escapism when they went to the cinema rather than interpreting their actions as also being the way they dealt with their emotions and living conditions (James 204). Into the $21^{\text {st }}$ century, the claims of companies promoting Virtual Reality headsets (VR) was that technology could make imagination unnecessary through immersive realism, which was a delusion regarding both the technology's capabilities and the experience that people were looking for and might have (Welsh 28-29; Williams). These examples in practice across history show something of the cultural attitudes to moving into and out of spaces of the imagination, and between formats. However, in terms of theory, there have been contrasting positions. During the early 2000s there were sharp exchanges between ludologists, some of whom were trying to establish a field for games theory on the basis that (online) games were a discreet and separate place apart, with different social conventions (Wardrip-Fruin and Harrigan). Others from a broad range of disciplines took a different position, seeing online games as an extension of previous cultural forms and social relations. Forty years earlier, in Fun in Games, Erving Goffman wrote about what he called the "gaming encounter" after observing that in most game situations the space of play has permeable boundaries, with players moving in and out, and with other non-players sometimes passing through. Moving to computer games, Tom Boellstorff argued that the online and offline are mutually constitutive (50), while Bart Simon claimed that one is "never playing alone" in online space, as one thinks about the experience when returning to offline space. While everyone may be inside the format of an online game, they also exist outside of it.

\section{My practice: video art}

8 I used the term video art to describe my practice earlier. The work I produce could be seen as machinima, the name created for videos made in games worlds (Kelland 24), but I have increasingly become unhappy with machinima as a label as it is now too often limited to being within the game rather than making outward connections. Michael Nitsche argued that machinima should be seen as a "media format based on procedural image production and reproduction" (114), whereas I want my work to be primarily artistically engaged. Video art has long established connections with pre-existing art 
forms, including literature, film, media and games, and developed as a way of comparing and contrasting these forms and the ideas in them. As such, it reflects my view that the digital is not exceptional (Marres 172) or completely different (Barnard 202), but another new technology among many that have played a part in the development of human cultural processes.

In terms of my presence in Second Life that generates video art, I see it as a matter of diverted attention, rather than a complete transfer of being into that space. I am thinking about how the three-dimensional space can be effectively reformatted into a two-dimensional video, and what other material can be drawn in from outside. Inside Second Life, format is constantly being reworked and disrupted: material is modelled in three dimensions, although the imported artwork had to be two-dimensional. I regard just recording the three-dimensional objects and actions made by others with Second Life as a failure - I should add my own creative interpretation. I often overlay the visual work with archive material, which has a different format, usually 4:3 rather than 16:9. By combining material from different places, digitised and in different formats, I am trying to overlay meaning to create layers, as "mixed realism" (Welsh), rather than complete immersion or separation.

In digital space, format takes a new meaning, pixels being visible only when the digital data goes through software. Audio takes the same route, and in this sense, sound is as formatted and reshaped as the visual. Audio is as significant to the sense of immersion as the visuals are, even if audio is often ignored (Gormanley), and I regard audio as important as visuals in my video art. However, audio and visuals are different in format. Audio is spatial, but it is not dimensional in the sense of having two and three dimensions, and audio is inherently linked to time in a way that visuals are not. So, in my way of working, format ceases to be fixed and is available for constant reinterpretation.

11 Future City (Canucci), as a video artwork, exists as a digital file and in Windows 10, on opening Properties, the Details tab shows it as being 1920 by 1080 pixels. This gives its ratio of contents but not its measurable size. As it can be viewed on a mobile phone or watched on a cinema screen, this only broadly describes its shape, not its dimensions (Bourriaud 71) or whether it will be back-lit or projected light, and so the "manner of arrangement or presentation" ("Format, n.") is neither constant nor immutable and reformatting is inevitable. Light and colour behave differently between the different formats of transmitted light, whether projected onto a screen or using a back-lit screen. There is also an inherent difference between transmitted light and reflected light, between RGB and CMYK colour respectively ${ }^{2}$. Each use has a different colour space and profile that affect the range, and so perceptions, of light, tone and colour (Henson) - something that is centrally important in visual perception yet often overlooked in the context of photomedia (McKenzie 127).

12 My video art brings together multiple formats of work, in line with the verb ("Format, v."), and for editing I use Lightworks software (Figure 1). The virtual world images were created digitally in the virtual space of Second Life. The archive images originated as a film, The City (Steiner and van Dyke), made during the late 1930s and now in the public domain, almost certainly on $35 \mathrm{~mm}$ celluloid film as a process of recording threedimensional activities on a two-dimensional stock. It has since been digitised, when the image formed as crystals was recognised and reformatted as pixels; millimetres into pixels. In turn, I take the digital and digitised and edit them together in video editing 
software. While the materiality and format changed over time, the names have continued, but are now metaphors. Video, as a word, originated in the 1930s, but came into common usage for magnetic tape recordings and was later adopted for any digital media ("Video, n."); in practice, film editing was not displaced by video editing until film makers started to use digital cameras instead of celluloid (Murch 77); as Grint and Woolgar commented, technology can be seen as text (70).

Visually, the pixels are what are played with when editing the videos together. The shape of the original archived film format was 4:3, which does not display full screen on most modern 16:9 computer screens. As the video from the virtual world is 16:9, bringing the two together requires changes to "shape and size" ("Format, n.") and so reformatting. The audio also plays with these technological changes; originally the film would have been recorded on magnetic tape but is now digitised. The music would not exist but for digitisation and the internet, as Creative Commons originated as a space where sharing and reuse was possible. Even then, video software editors are very specific about which audio formats they can handle, so I often have to convert them in software (Audacity) to suitable formats.

For Maurice Merleau-Ponty, montage and editing were essential to film, and a form of syntax $(1964,55)$. Indeed, that it is how I feel when I am editing; it is a process of translation between two syntactic forms. Translation is an interesting concept to apply to how people reinterpret visual images and audio forms, but that would form another journal article in itself. In summary, in translation theory, mediation is not about language rules determining outcomes, but instead is something people do to try to communicate effectively across boundaries, and in so doing words bridge culture and people make choices about the several possible meanings that all utterances have (Bellos). Indeed, David Bellos argues film is a useful tool for considering the many and multiple ways that meaning is conveyed simultaneously (71). So, returning to visual and audio, these clearly do not transfer or convert perfectly from one format to another, and always generate new meanings and ways of interpreting meaning (Merleau-Ponty 1964, 58), and this is where I can add value through art. Some works call for a later reworking, as I need time to come to terms with what they contain, for them to speak back to me. As the playwright Tom Stoppard said in interview, "There is a degree of trial and error. The art is to control the flow [...and] correction is not always authorial. A good production is in a permanent state of self-correction, one hopes" (143).

15 Playing with video to reformat and edit it reveals digital material as not being a "void [as many theorists have seen it] but being full of many possible realities, like an image space" (McKenzie 70). A screenshot of Lightworks, my preferred editing software, in use with Future City (Canucci) is shown in Figure 1. Top right is a list of the content that was imported to work with, and the lower bars show how it has been placed, edited and cut. On the audio tracks bars, beginning with an A, there is a visual representation of the sound wave. Where the cuts lie is an editorial decision, linking and linked to visual appearance and sound; time is critical.

The button marked Effects in the bottom right brings up a list of video effects for changing the appearance and qualities of the work, from simply size and position of individual parts to more complex mixing and transitions of the layers. It is the means of creating interactions between the different material and formats, by conscious frame by frame editing. Effects are marked by small squares at the left side of the video tracks 
(bars marked V) and the long green bars in this area, and the segments in the FX bars. The long green bars and FX segments always work across multiple layers.

Figure 1. Editing Future City (Canucci) in Lightworks software. Digital information made visible in multiple ways.

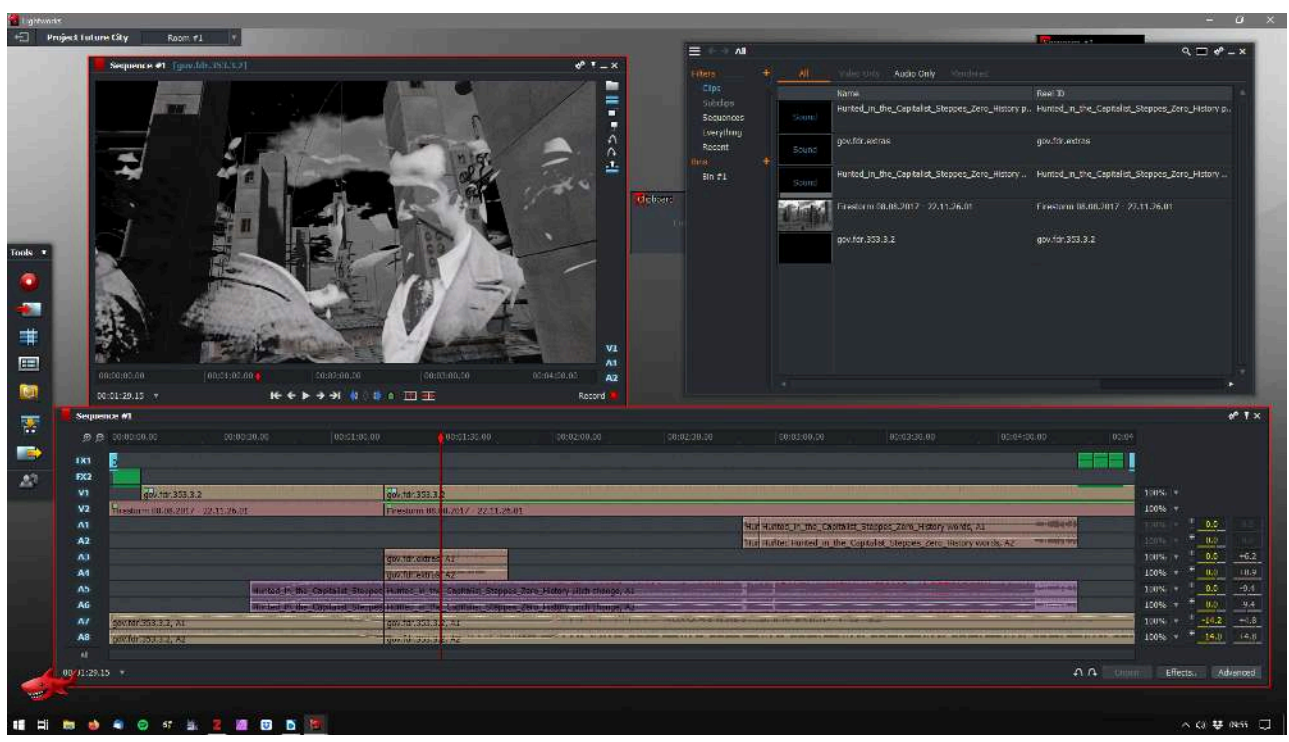

(c) Tess Baxter.

17 A factor in working with archive material is proportions and measures, and is manipulated with the DVE effect, which shows as a small square. Lightworks sets up the 4:3 archive film frame within the 16:9 format, and to cover the whole screen area, the archive film has to be either stretched in width, distorting the ratio and appearance, or stretched in height, retaining the ratio but cropping the original image. It is another editorial decision based on aesthetics.

The long green bar shows, in this case, a lumakey effect, which is a blend of the layers based on brightness. The approach was an aesthetic decision based not on a predictable outcome, but on how the two images interacted, and balanced so the foreground and background emerged out of each other visually. In so doing, it engages the two works in conversation about their two different perspectives on the future across time and engages in the differences between the artistic film formats.

Going back to Pierre Lévy, both these video forms are equally real; calling the archive real and the virtual imaginary or illusory is a false position to take. Not even academic writing can claim to be fact over fiction, for as Clifford Geertz's claimed, academic writings are "fictions in the sense that they are 'something made,' 'something fashioned' - the original meaning of fictiō - not that they are false, unfactual, or merely 'as if thought experiments" (15). For Lévy there is a cyclical flow between the virtual as ideas, based on the Latin root of the word in virtus (Müller 296), and the actual as things. The virtual exists as a set of possibilities that may be actualised, and in that actualisation moves from being an actual idea or a problem to a solution. In turn, there is a reverse process of virtualisation, from a given solution and to a different problem (Lévy 27). Lévy sees the virtual and actual as two different ways of being, rather than static "things", and a continuing cycle is what I work with in editing the video. Adopting a printmaking practice was a decision to continue the cycle further. 

"hallucinatory pastiche" that Jai McKenzie (98) referred to, something generating a third, alternate space that plays with the flow of space-time by fragmenting the past into what is the present. By fusing contemporary music and virtual world material with historic material, I do this explicitly; they are both blended together to make a new work that stands with the visuals. In using archive material, I am not trying to return to the past or to presume that there is a literal historical interpretation, but to detach this found image from its former everyday familiarity to set it against new material, so that the old and new become "entwined" (Leonard). When the artist John Stezaker was asked if images died, he responded: "Yes, but with images this is not the last word. They can come alive again. Indeed a kind of death of the image, in obsolescence or dysfunction, is often required for it fully to come alive as an image" (Stezaker and Warstat 75). This is my intent. Digitised archive films are not simply reproductions of an original film on celluloid, but are "virtual objects [that] can be seen as illuminating the potential meanings of art and other objects", and, as a consequence, "virtuality should be understood as a complex cultural interpretation of objects that forces us to rethink the tangible and intangible imprints of our cultural history" (Müller 296). As such, they can also be seen as "salvage narratives", as "restorations of one moment in time, or adaptive reuse, which brings the past and present together in continuous narrative" (Potteiger and Purinton 22). Consequently, an image of happenings formed in one place is viewed in another place, where it takes on another set of meanings in that new context (Tagg 4).

21 An extension of the video is the poster, shown in Figure 2.

Figure 2. Poster for Future City (Baxter and Canucci). A still image can represent the moving image, but it is not a moving image.

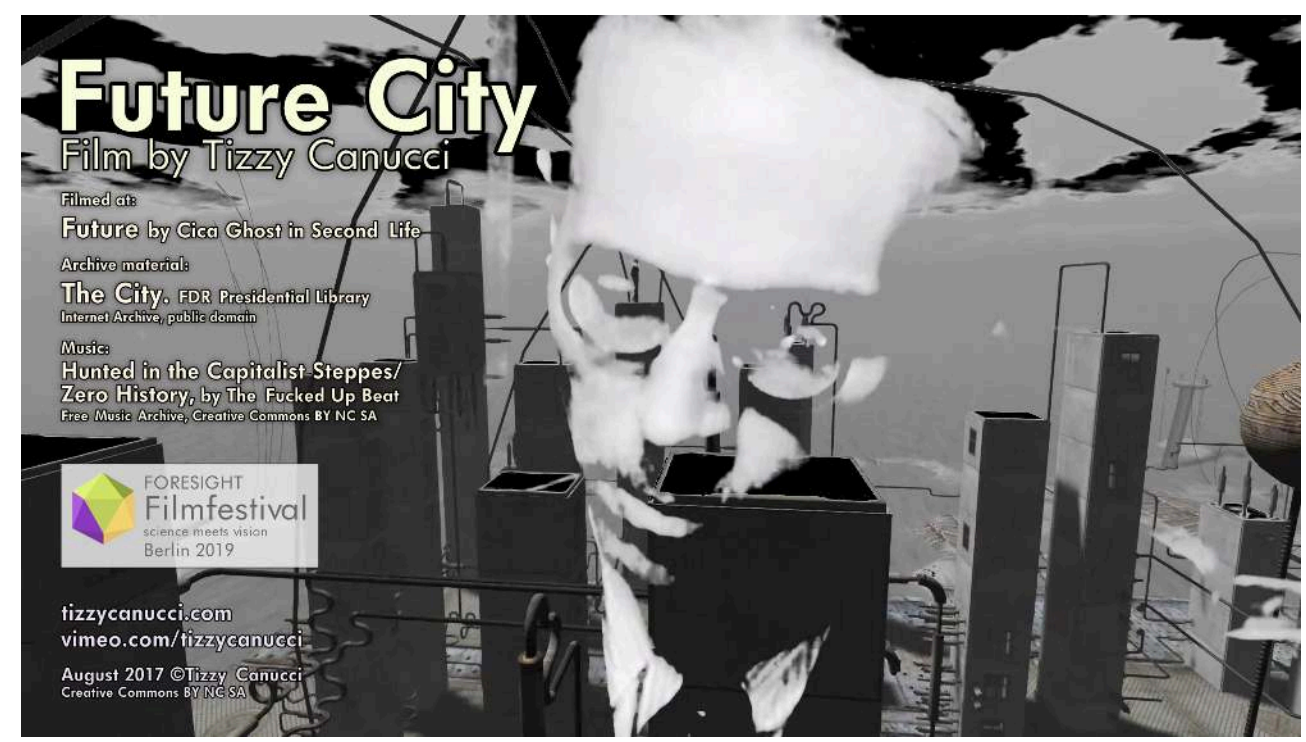

(c) Tess Baxter.

While the poster can represent the moving image, it is not a moving image as it is both visually static and fixed in time, and as Susan Sontag said of photographs, they "are a way of imprisoning reality, understood as recalcitrant, inaccessible; of making it stand still" (163). Equally, the video or film is not just the sum of its individual images, but a perceptual object and a temporary gestalt (Merleau-Ponty 1964, 54), with a dynamic 
relationship moving across time. This is emphasised by the silence of the poster when the video had a carefully edited audio with an interplay between the archive's soundtrack and contemporary music. The poster reformats the visual characteristics of the moving image, the only thing remaining the same being the number of pixels: 1920 $\mathrm{x} 1080 \mathrm{px}$. This does not mean that either the still or moving image is superior, even if the still image could not exist without the original moving image. What is significant is context. Figure $\mathbf{2}$ has meaning in itself as a poster format, an image to spend time with along with credits as text; a visual summary.

\section{From digital image format to still image printmaking format}

As I mentioned earlier, I adopted a printmaking practice to continue the cycle of actual and virtual further; the poster in Figure 2 is a half way point; still digital, but not a moving image. Printmaking reconceptualises the still image and tests the academic categories of media and mediation. Future City exists as prints, digitally produced and made through printmaking, and video; different ways of making things that continue to exist in their own right and with a relationship to each other, so challenging abstracted conceptual theories around mediation and mediatization (Billig 111).

In this range of formats, there is the question of how it can be seen, and so who can see it. The visual part of digital video art is made of pixels which are invisible until displayed on a suitable device, in effect, an intermediary for the media; "the screen makes visible the invisible; it is in the interface between information and image" (McKenzie 82). While you cannot see the printmaking directly nor feel its texture (unless I send you one of the edition prints), even with a digital reproduction no intermediary is necessary even online; you simply need to be in the same space as the print with the light on (9). The concept of transmediality can imply that media content can exist independently of mediation processes (Larrue and Vitali-Rosati), but like Schrödinger's cat, does a visual image exist if it cannot be viewed? In their conclusion, Larrue and Vitali-Rosati claim "it is impossible to identify a single and determined mediating conjuncture in abstracting other conjunctures which participate in the mediating process" (27). In theory, if you are reading this paper online, the images would only be present because of the technology acting as intermedia. But in talking about a cyclical process, you have to decide to stop somewhere, or it becomes abstracted to the point where practice and practical experience vanish in the service of media and mediatisation theory, like the Cheshire Cat in Alice's Adventures in Wonderland:

"Well, then," the Cat went on, "you see, a dog growls when it's angry, and wags its tail when it's pleased. Now I growl when I'm pleased, and wag my tail when I'm angry. Therefore I'm mad."

"I call it purring, not growling," said Alice.

"Call it what you like," said the Cat...

"All right," said the Cat; and this time it vanished quite slowly, beginning with the end of the tail, and ending with the grin, which remained some time after the rest of it had gone.

"Well! I've often seen a cat without a grin," thought Alice; "but a grin without a cat! It's the most curious thing I ever saw in my life!". (Carroll, chap.VI). 
looking more closely at the practice, the process of photopolymer etching is complex and I will summarise, but Photopolymer Photogravure (Harmon) is a good full practical guide for more detail ${ }^{3}$. An individual still image is selected and saved from the video work. That image is converted to black and white, the contrast adjusted, and it is then printed on transparent acetate sheets. The acetate is placed on the photopolymer plate, which has a light sensitive surface, and is exposed to ultraviolet light for a carefully selected length of time. The contrast must be reduced considerably on the acetate because of the way light passes through the acetate and the characteristics of the photopolymer surface. The areas where there is no ink on the acetate harden and the areas concealed by ink stay soft, so when the plate is washed in water, the soft areas flush away and an etched surface is created. The whole plate is then left exposed, to harden, first in ultraviolet light and then in warmth. It is then ready for the printing process; the hardened plates are shown in Figure 3.

Figure 3. The three Future City photopolymer plates after use; the prints are shown in Figures 4, 5 and 6. The colour difference is a superficial technical one; the plate on the left was manufactured under the tradename of Toyobo and the two on the right, Miraclon.

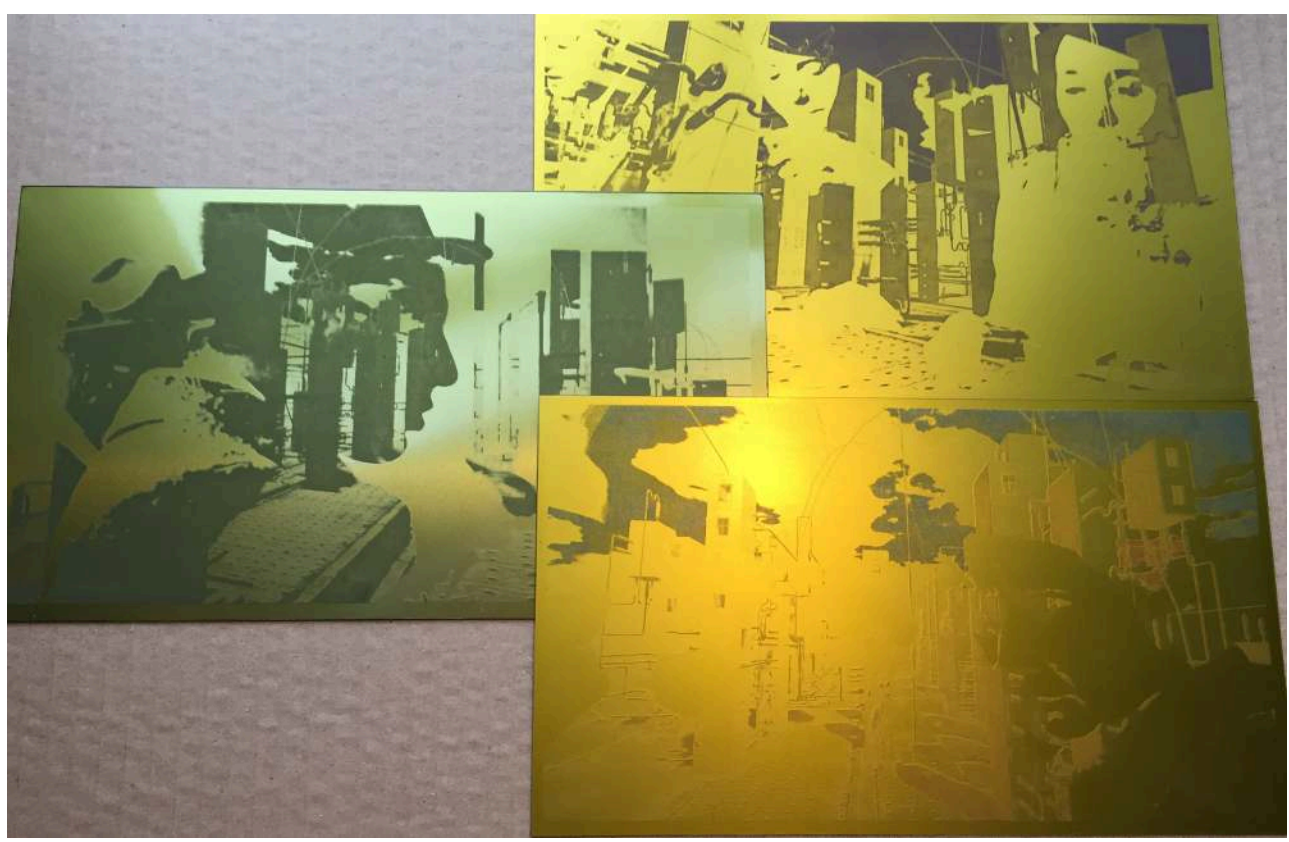

(C) Tess Baxter.

The hardened plate is spread with ink, then wiped down; the greater the area of etch, particularly when some areas have been more deeply etched, the more ink is held in the plate. However, if the contrast and timings were wrong earlier, the photopolymer may have etched away completely and will no longer hold ink. It is then passed through the mechanical press between a flat steel bed and a roller, which pushes the plate hard against dampened paper, so transferring the ink, and the image, to the surface of the paper.

The relationship with materiality is significant, while bearing in mind that "[d]igital worlds [...] are neither more nor less material than the worlds that preceded them" (Miller and Horst 4), with human perception adapting to new technologies to impose a revised sense of normality. However, while materiality may be constantly present, it does not have the same qualities. For instance, magnetic tape or photographic film 
record using crystals of varying shape and pattern, unlike the regular pattern of dots of digital data. A photopolymer etching is a textured surface in three dimensions, not a regular pattern of dots on a two-dimensional surface. Furthermore, how ink lies on paper depends on the qualities of the pigments in ink, how they are spread on the plate by the maker's hand, the pressure of the press, and the qualities of the paper. Each of these material differences results in a new format for any work that passes through the process.

Some of the resulting prints are shown in Figures 4,5 and $\mathbf{6}$. They are $20 \times 11 \mathrm{~cm}$, but unlike a digital print, pixels and millimetres are not dependent on each other, although the relationship affects the aesthetic qualities. As such, printmaking is a reinterpretation and translation rather than a reproduction, and how the plates are made and formatted gives them a different kind and level of meaning.

Figure 4. Future City: A Hat (Baxter). Number eight out of a limited-edition print of twenty-five.

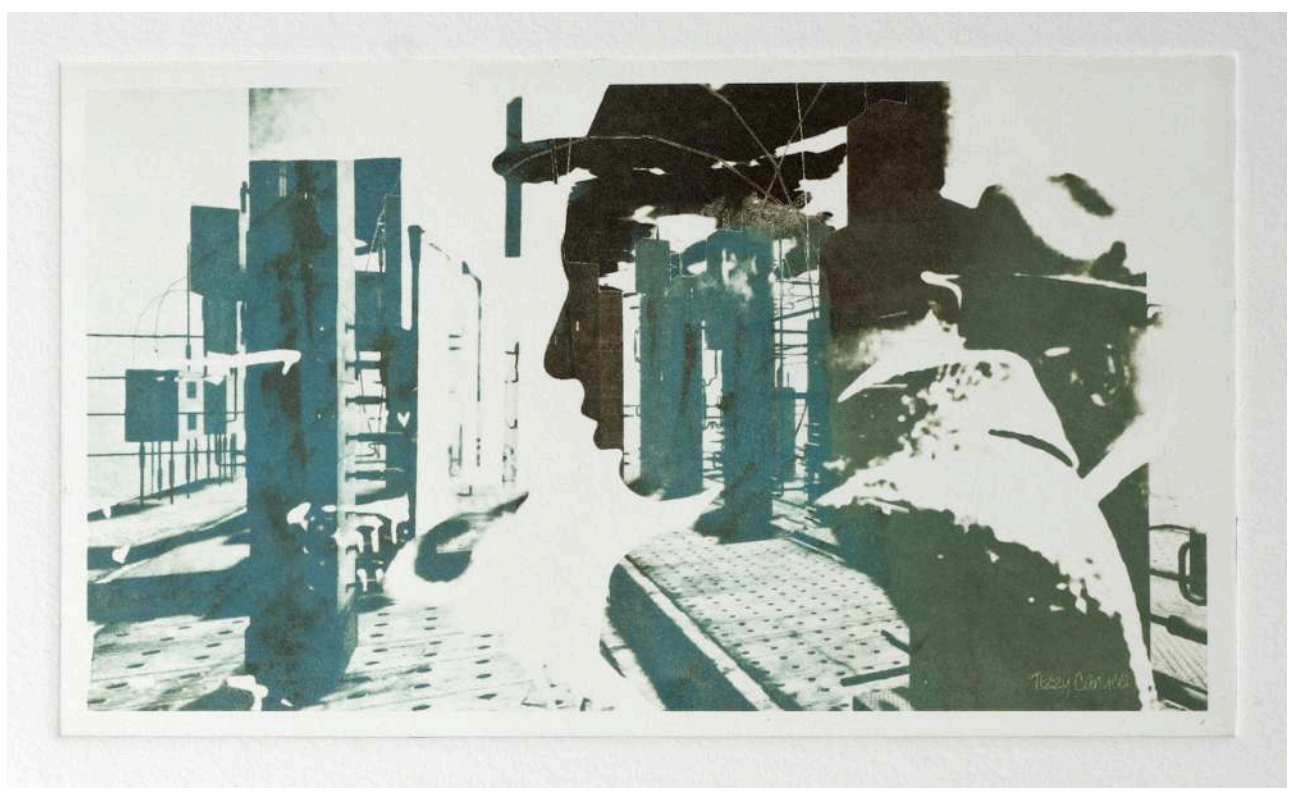

(C) Tess Baxter

As outlined above, this form of hand printing is different from digital printing. At its most basic, they both depend on the materiality of the ink and how it is spread on paper. However, the size of the image, the quality of the print technology, and the skill and awareness of the operator, are very different factors that vary between printmaking and a computer print. The former is a hand-crafted technique depending on visual interpretation during the printing stage, and the latter is a technical one depending on visual interpretation before the printing stage. The digital print depends crucially on resolution and the number of pixels available to be printed as dots per centimetre or dots per inch (dpi) on the page, or the data, and this determines the dimensions of the image on paper that is visually acceptable. While resolution is important for both formats, with hand printing how the printmaker interprets the plate and applies the ink is more significant than the data and the specialised capabilities of the technology.

The four images shown in Figure $\mathbf{5}$ are prints from another plate (Baxter, Future City: The Coffee) made from Future City (Canucci). While a still digital image made from the 
video art would remain constant and only alter in appearance by deliberate manipulation in software or a faulty printer, each print in this hand-made edition of twenty-five prints has very different visual qualities, which demonstrates the importance of interpretation by the printmaker.

Figure 5. Future City: The Coffee (Baxter). Four prints out of the edition of twenty-five, shown cropped and overlapping. Each is printed from the same plate, and this shows the variation in inking.

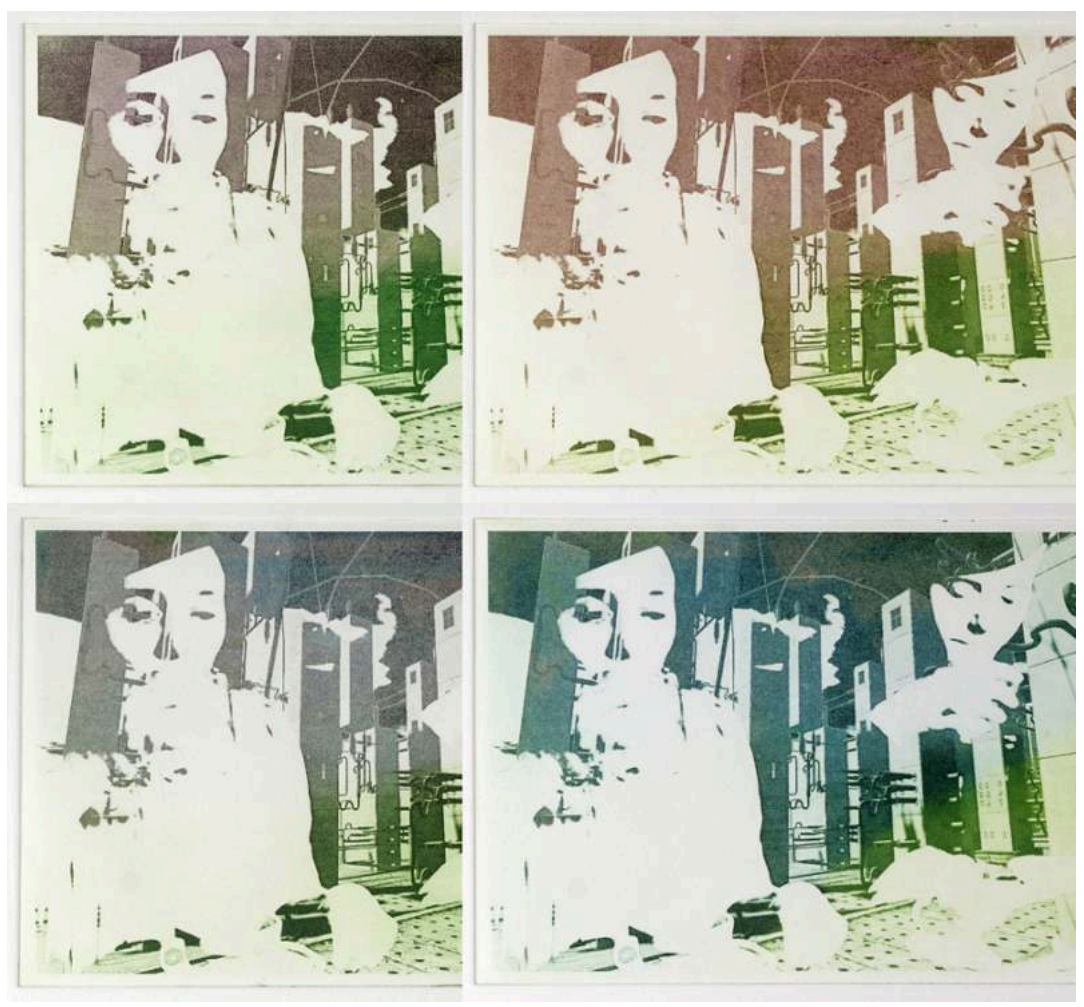

(C) Tess Baxter. 
Figure 6. Future City: The Look (Baxter). Number one out of a limited edition of twenty-five prints.

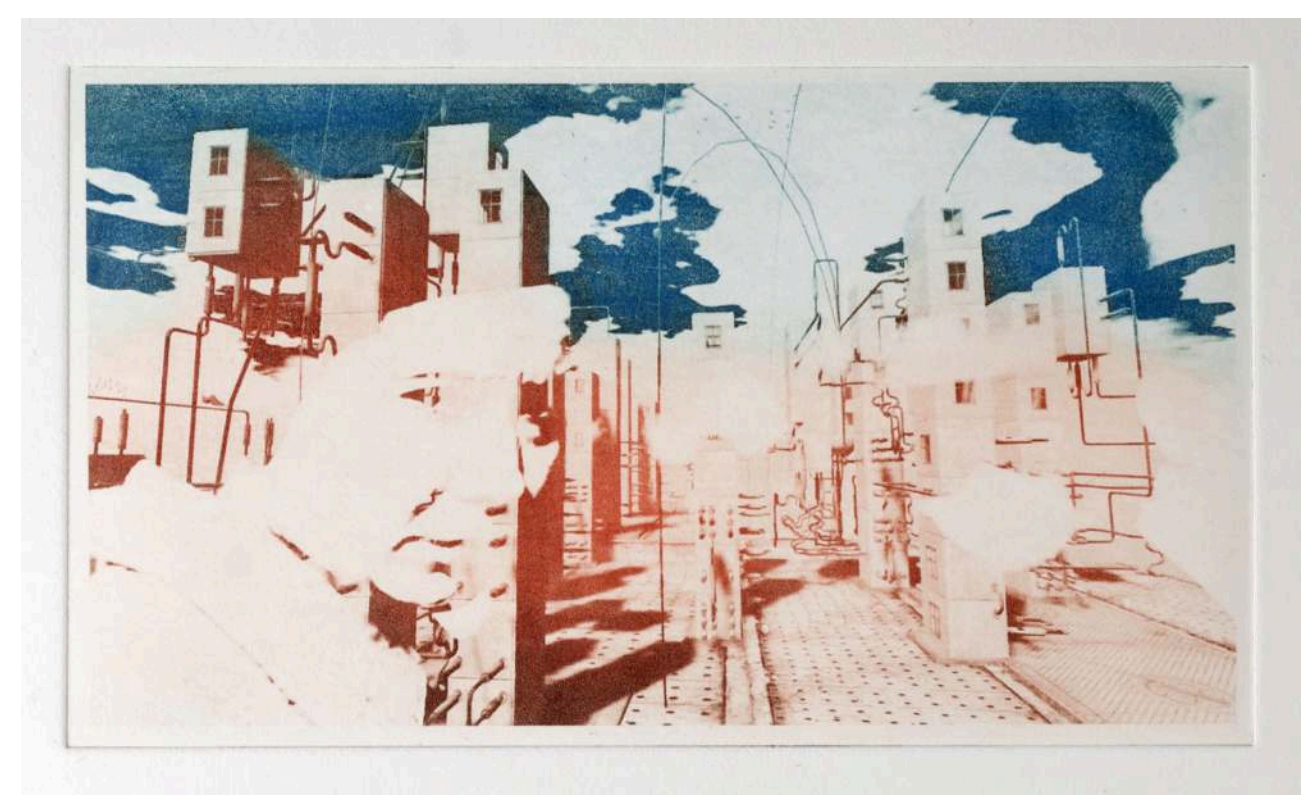

(C) Tess Baxter.

An important idea that I wanted explore in Future City (Canucci), apart from connecting archive to contemporary, was human presence in virtual and actual space, and the visual results of this are shown in all the images of finished printmaking (Figures 4, 5 and 6). Virtual worlds may come out of the imagination of human beings, and people may be present as avatars in the spaces, but they are only there in passing. Only one avatar is visible in the video, which is throwing itself off the top of one of the towers in the opening sequence; barely visible, I regarded my inclusion of that avatar's action in the video as an ironically humorous statement about the lack of presence of avatars in the space. In contrast, people crowd around in a cityscape in the archive film, going about their daily tasks; a very definite presence doing definite things. My original idea was not to compare or contrast these two forms, but to populate the video of the virtual world with people, to introduce life to the virtual city. I thought of setting them next to each other, perhaps with some text, a technique I used in Breaking Ice (Canucci) (Figure 7), taking care to use the text as a complementary dialogue not an explanation (Martin and Álvarez López). My ideas for Future City (Canucci) changed in the editing, an example of where art speaks back to the creator. It seemed to be more effective to put the visual images into conversation, one format overlaying the other, exchanging aesthetically and in dialogue with each other. This is the value of research, not just creativity, as exploration and discovery, rather than following assumptions or a hypothesis. 
Figure 7. A still from Breaking Ice: a 70-year story (Canucci). Public domain archive film, The Great Northern Sea Route (Frolenko) (left) alongside virtual world video (right). Writing is never unambiguous, but academic conventions assume them to be, which gives them ascendency over visuals. Here, the text is a commentary, not an explanation. The video is formatted to give the two images their own space to be "read" in their own visual language and are equal partners with the text (Martin and Álvarez López).

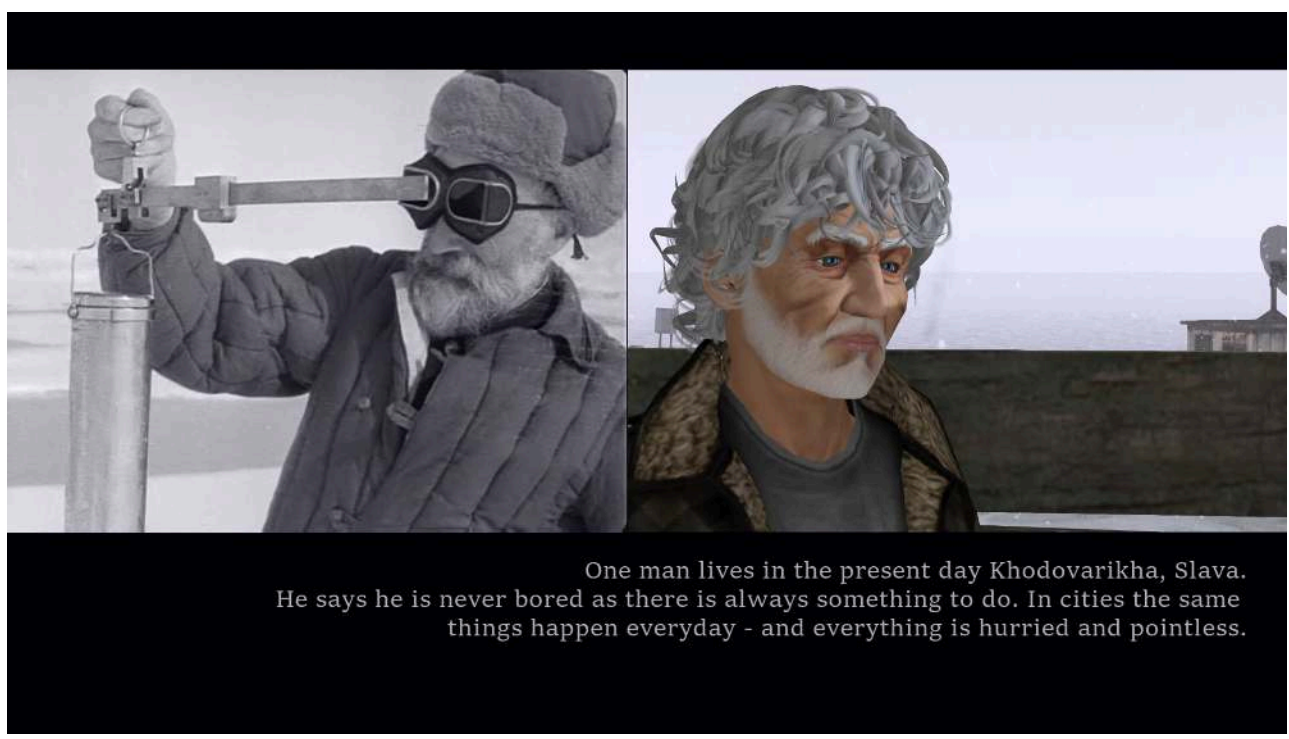

(C) Tess Baxter

\section{Concluding thoughts}

Art practice is a way of not just seeing format as dimensions, but a way of playing with and exploring its multiple facets. In my own practice, the video art that works across virtual worlds, literature, film and archive material, so spanning the digital to digitised, which I have consequently transferred back to print, has been particularly rich. This flow between digital, digitised and craft production using ink connects with the theory of Pierre Lévy, who saw the actual and the virtual as being in a continual cycle and that people go into and return from different realities (16). Furthermore, I see it not only as a process of reinterpretation, but of translation across multiple visual and audio forms.

Drawing on the history of definitions ("Format, v."; "Format, n.") is helpful in seeing how they fit across time in cultural processes and their relationship with space, immersivity and social engagement; context is important in understanding how formats relate. In the case of virtual worlds as the space out of which I make my art, thinking about them as games is constructive; the sense of entering and leaving, but never remaining totally inside (Goffman) and of being immersed mentally but not totally physically (Merleau-Ponty 1969, 136). This relates back to Lévy's argument about the actual and virtual both being real. The layering techniques of my video art connect to Timothy J. Welsh's concept of "mixed realism", as I work with artforms that are different in origin and have to be reformatted, reinterpreted and blended together so that they converse with each other. In this, it is a form of translation, of making sense of connections and meanings and between what is said and the reasons behind it having been said (Bellos 69, 72). This is particularly the case with audio and visual, which are equally important in my video art. 
The difference between the still and the moving image is another form of reformatting, with implications for perception. Film or video is not just a sequence of still images, but their position relative to one another across time matters (71); still images have their own independent meaning (Sontag 163). The way that humans perceive the transmitted light from a screen and the reflected light of pigments off paper is quite different (McKenzie; Wickens 55-90), which makes it necessary to make practical technical choices in colour formats and spaces (Henson). Printmaking demands craft-based decisions by the printmaker based on their perception of light, as well as material considerations of ink and paper. On an inkjet printer, it is mainly a technical choice, with the technology taking data as pixels and placing them as dots on the paper. Printmaking is a different, hand crafted, mechanical process, where the data has been reduced to etchings on a print plate (Fig. 3). The dimensions, the technical issues of plate-making, pigments, how the ink spreads are all related to format. They are rarely resolved immediately but take a period of playing with (Harmon) to find a good reinterpretation or translation of the original screen image; they will never be the same. Ultimately, this kind of research shows the value of discovery and exploration, and the worth of playing with format.

\section{BIBLIOGRAPHY}

\section{Works cited}

BARNARD, Stephen R. 'Digital Sociology's Vocational Promise'. Digital Sociologies. Ed. Jessie Daniels et al. Bristol: Policy Press, 2017. 195-210.

BELLOS, David. Is That a Fish in Your Ear?: Translation and the Meaning of Everything. London: Penguin, 2012.

BILLIG, Michael. Learn to Write Badly: How to Succeed in the Social Sciences. Cambridge: Cambridge University Press, 2013.

BOELLSTORFF, Tom. "Rethinking Digital Anthropology." Digital Anthropology. Ed. Heather A. Horst and Daniel Miller. London: Berg Publishers, 2012. 39-60.

BOURRIAUD, Nicolas. Relational Aesthetics. Transl. Simon Pleasance and Fronza Woods. Dijon: Les Presses Du Réel, 1998.

BRAY, Joe. The Female Reader in the English Novel: From Burney to Austen. Abingdon: Routledge, 2008.

CARROLL, Lewis. Alice's Adventures in Wonderland. 1865. Ed. Arthur DiBianca and David Widger. Project Gutenberg. 2020 ed. URL: https://www.gutenberg.org/files/11/11-h/11-h.htm (page accessed 20 November 2020).

CREATIVE COMMONS. Creative Commons - Attribution-NonCommercial-ShareAlike 4.0 InternationalCC BY-NC-SA 4.0. URL: https://creativecommons.org/licenses/by-nc-sa/4.0/ (page accessed 28 November 2020). 
EMERSON, Lori. Reading Writing Interfaces: From the Digital to the Bookbound. Minneapolis: University of Minnesota Press, 2014.

FROLENKO, V. The Great Northern Sea Route. 1947. Internet Archive/ National Archives and Records Administration. 2011. URL: http://archive.org/details/gov.archives.arc.44539 (page accessed 4 October 2017).

GEERTZ, Clifford. The Interpretation of Cultures: Selected Essays. London: Fontana, 1973.

GOFFMAN, Erving. "Fun in Games." Encounters: Two Studies in the Sociology of Interaction. Indianapolis: Bobbs-Merrill, 1961. 17-84.

GORMANLEY, Stephen. "Audio Immersion in Games - a Case Study Using an Online Game with Background Music and Sound Effects.” The Computer Games Journal 2:2 (Sept. 2013): 103-124. GREGORY, Karen, et al. “Introduction.” Digital Sociologies. Ed. Jessie Daniels et al. Bristol: Policy Press, 2017. xvii-xxx.

GRINT, Keith, and Steve WOOLGAR. The Machine at Work: Nihilism and Hermeneutics in Post-Modern Culture: Technology, Work and Organization. Cambridge: Polity Press, 1997.

HARMON, Clay. Polymer Photogravure: A Step-by-Step Manual, Highlighting Artists and Their Creative Practice. London, Routledge, 2019.

HENSON, Keith. "Colour Managed Workflow." Northscape. URL: http://www.northscape.co.uk/ colour-managed-workflow (page accessed 9 April 2017).

JAMES, Robert. Popular Culture and Working-Class Taste in Britain, 1930-39: A Round of Cheap Diversions? Oxford: Oxford University Press, 2010.

KELLAND, Matt. "From Game Mod to Low-Budget Film: The Evolution of Machinima." The Machinima Reader. Ed. Henry Lowood and Michael Nitsche. Cambridge, MA: MIT Press, 2011, 2335.

KRZYWINSKA, Tanya, and Geoff KING. Screenplay: Cinema/Videogames/Interfaces. London: Wallflower Press, 2002.

LARRUE, Jean-Marc, and Marcello VITALI-ROSATI. Media Do Not Exist: Performativity and Mediating Conjunctures. Transl. John Detre and Beth Kearney. Amsterdam: Institute of Network Cultures, 2019.

LEONARD, Robert. “John Stezaker: Twice Removed, Ex. Cat.: John Stezaker: Lost World.” Robert Leonard Contemporary-Art Writer And Curator, 2017. URL: http://robertleonard.org/john-stezakertwice-removed (page accessed 8 January 2019).

LEVY, Pierre. Becoming Virtual: Reality in the Digital Age. Transl. Robert Bononno. London: Plenum Trade, 1998.

MARRES, Noortje. Digital Sociology: The Reinvention of Social Research. Cambridge: Polity, 2017.

MARTIN, Adrian, and Cristina ÁLVAREZ LÓPEZ. "Writing in Images and Sounds." Sydney Review of Books, Feb. 2017. URL: http://sydneyreviewofbooks.com/writing-in-images-and-sounds (page accessed 4 February 2017).

McKENZIE, Jai. Light and Photomedia: A New History and Future of the Photographic Image. London: I B Tauris, 2014.

MERLEAU-PONTY, Maurice. Sense and Non-Sense. Transl. Hubert L Dreyfus and Patricia Allen Dreyfus. Evanston, IL: Northwestern University Press, 1964. 
MERLEAU-PONTY. The Visible and the Invisible. Edited by Claude Lefort, Transl. Alphonso Lingis. Evanston, IL: Northwestern University Press, 1969.

MILLER, Daniel, and Heather A. HORST. "The Digital and the Human: A Prospectus for Digital Anthropology." Digital Anthropology. Ed. Heather A. Horst and Daniel Miller. London: Berg Publishers, 2012. 3-35.

MÜLLER, Klaus. "Museums and Virtuality." Museums in a Digital Age. Ed. Ross Parry. London: Routledge, 2009, 295-305.

MURCH, Walter. In the Blink of an Eye: A Perspective on Film Editing. $2^{\text {nd }}$ ed. Los Angeles: SilmanJames Press, 2001.

NITSCHE, Michael. "Machinima as Media." The Machinima Reader. Ed. Henry Lowood and Michael Nitsche. Cambridge, MA: MIT Press, 2011. 113-25.

OXFORD ENGLISH DICTIONARY Online, Oxford University Press, 2020. "FORMAT, N.” URL: https:// www.oed.com/view/Entry/73446 (page accessed 18 November 2020).“FORMAT, V.” URL: https:// www.oed.com/view/Entry/73447 (page accessed 18 November 2020). "VIDEO, N.” URL: https:// www.oed.com/view/Entry/223260 (page accessed 23 November 2020).

POTTEIGER, Matthew, and Jamie PURINTON. Landscape Narratives: Design Practices for Telling Stories. New York: John Wiley \& Sons, 1998.

SIMON, Bart. "Never Playing Alone: The Social Contextures of Digital Gaming." Loading..., 1:1 (Mar. 2007). URL: http://journals.sfu.ca/loading/index.php/loading/article/view/20 (page accessed 11 August 2015).

SONTAG, Susan. On Photography. New ed. London: Penguin, 1979.

STEZAKER, John, and Andrew WARSTAT. “An Interview with John Stezaker.” Parallax 16:2 (May 2010): 68-78. URL: http://robertleonard.org/john-stezaker-twice-removed (page accessed 8 January 2019).

STOPPARD, Tom. "Ask an Author: Tom Stoppard. Interviewed by James McConnachie." The Author: Journal of the Society of Authors 130:4 (winter 2019): 143.

TAGG, John. The Burden of Representation: Essays on Photographies and Histories. New York: Palgrave Macmillan, 1988.

WARDRIP-FRUIN, Noah, and Pat HARRIGAN, ed. First Person: New Media as Story, Performance, and Game. Cambridge, MA: MIT Press, 2004.

WELSH, Timothy J. Mixed Realism: Videogames and the Violence of Fiction. Minneapolis: University of Minnesota Press, 2016.

WICKENS, Andrew P. Introduction to Biopyschology. $3^{\text {rd }}$ ed. Basingstoke: Prentice Hall, 2009.

WIGHT, C. “Caxton's Chaucer - The Canterbury Tales.” British Library. URL: https://www.bl.uk/ treasures/caxton/canterbury.html (page accessed 15 December 2018).

WILLIAMS, Dmitri. “Community Is the 'Killer App' Missing from Virtual Reality.” Los Angeles Times, 27 December 2016. URL: https://www.latimes.com/opinion/op-ed/la-oe-williams-virtualreality-20161227-story.html (page accessed 27 December 2016). 


\section{Film cited}

STEINER, Ralph, and Willard VAN DYKE. The City. 1939. Digitizing sponsor, American Institute of Planners, through Civic Films, Inc. (2012). FDR Presidential Library \& Prelinger Archive on Internet Archive. URL: https://archive.org/details/0545_City_The (page accessed 17 August 2017).

\section{Printmaking and video art}

BAXTER, Tess. Future City: A Hat. 2020.

BAXTER, Tess. Future City: The Coffee. 2020.

BAXTER, Tess. Future City: The Look. 2020.

BAXTER, Tess, and Tizzy CANUCCI. Future City: Poster. 2020.

CANUCCI, Tizzy. Breaking Ice: A 70-Year Story, 2017. URL: https://vimeo.com/236807905.

CANUCCI, Tizzy. Future City, 2017. URL: https://vimeo.com/230061160.

\section{NOTES}

1. Where I refer to printmaking I am referring specifically to the mechanical craft practice of ink on paper. Print applies to digital prints from computers, or, as a word with general meaning, refers to both.

2. The human eye essentially perceives light as RGB, red, green and blue (Wickens 74), and transmitted light from screens uses that combination. To get similar effects from reflected light, the pigments of CMY, cyan, magenta and yellow are required, with $\mathrm{K}$, black, to provide hue (Henson).

3. This type of printmaking is given a variety of overlapping names variously including the words photopolymer etching and photogravure printmaking. Photo refers to it being a darkroom photographic process, polymer to the photo-sensitive plastic coating, and etching and gravure to a wider group of traditional printmaking techniques that involve ink being held in marks made into the surface of the plate, rather than ink being applied to the surface, as in relief printing.

\section{ABSTRACTS}

Formats have an interacting range of qualities that practice based research can explore, so testing and questioning theory; they are more than dimensions. Video art can play with space, light and sound, through a choice of materials, including visuals and audio. I make video art out of the virtual world of Second Life with its interplay of two-dimensional textures and threedimensional objects. Editing this virtual world digital video with digitised archive film, 
contemporary music and literature explores how the formats used by multiple creators across time can interact, so exploring meanings through reinterpretation and translation. Taking still images from that video art into printmaking using photogravure etching, a hand-crafted method of mechanically pressing ink on paper, considers the translation of light on screen to ink on paper, and explores format from another position. Going from moving image to still images changes the relationship with time and distance, and from ratios in pixels to dimensions in millimetres.

Les formats possèdent un éventail de qualités interactives que la recherche pratique peut explorer, mettant ainsi à l'épreuve la théorie. L'art vidéo peut jouer avec l'espace, la lumière, le son, et les matériaux, y compris des éléments visuels et audio. Je fais de l'art vidéo à partir du monde virtuel de Second Life, m'inspirant de son jeu de textures bidimensionnelles et d'objets tridimensionnels. Je monte les vidéos numériques en mixant des films d'archives numérisés, de la musique contemporaine et de la littérature et propose d'explorer comment le travail de plusieurs créateurs produit des sens différents par le biais de la réinterprétation et de la traduction. J'ai utilisé la technique de photogravure, une méthode artisanale de pressage mécanique, pour retravailler des images fixes de l'art vidéo, traduire la lumière à l'écran par des jeux d'encre sur le papier et ainsi explorer le format depuis un autre angle. Cette conversion de l'image animée à l'image fixe change le rapport au temps et à la distance.

\section{INDEX}

Keywords: video art, printmaking, visual, audio, practice led, virtual world, time and space, editing, format, archive film

Mots-clés: art vidéo, photogravure, visuel, audio, recherche pratique, monde virtuel, temps et espace, montage, format, film d'archives

\section{AUTHOR}

\section{TESS BAXTER}

Lancaster University, UK

After a background in photography and writing, Tess Baxter started working with video in 2015. She began experimenting with video art in Second Life (also known as machinima) as an artform soon after, working under her pseudonym of Tizzy Canucci. She has now produced over sixty pieces of video art and has been invited to show at many art exhibitions. Her work has been selected for the Supernova Digital Animation Festival in Denver each year from 2016-2019. During 2019, her work was selected for a Science and the Future film event at Urania in Berlin, and she exhibited at the academic conference attached to the MEGA/MIGS19 games event in Montreal. She has a wide range of influences, informed by her previous background in writing, photography and editing. She is particularly interested in the flow between realities, setting 'real world' film, animation, music video and poetry against virtual material. This interest has led to her developing her practice into printmaking over the last 18 months. She reworks her images from Second Life from digital and light into ink on paper. Her current practice spans both moving and still image, light and ink. Tess was awarded a PhD in Contemporary Art at Lancaster University in February 2021. 